RELACult - Revista Latino-Americana de Estudos em Cultura e Sociedade e-ISSN 2016/Atual: 2525-7870 | e-ISSN 2015/2016: 2447-018X

\title{
"Deise Nunes- Daqui para o Brasil e o Mundo": A representação da mulher negra em concursos de beleza
}

\author{
"Deise Nunes- Aquí para Brasil y el mundo": Representación de la mujer \\ en negro en concursos de belleza \\ "Deise Nunes- Here to Brasil and the world": Representation of black \\ woman in beauty contests
}

Ma. Beatriz Floôr Quadrado ${ }^{1}$

\begin{abstract}
Resumo
O presente trabalho é parte de uma pesquisa de dissertação de mestrado sobre um concurso intitulado "Miss Mulata" da cidade de Arroio Grande (RS), neste recorte, pretende-se abordar a trajetória de Deise Nunes. Ela participou deste certame em 1982, e de muitos outros concursos, até chegar ao título de Miss Brasil em 1986. Deise ter sido coroada como representante do Brasil se contrapõe a vários estereótipos de beleza, contrário a um padrão de branquitude, em que brancos são super valorizados. Deise causou surpresas ao representar o Estado Gaúcho e o país da miscigenação que sempre havia enviando para o Miss Universo mulheres brancas, e, preferencialmente, loiras. A principal metodologia utilizada nesta pesquisa foi a história oral, além de pesquisa em acervos de jornais.
\end{abstract}

Palavras- chaves: Deise Nunes; concursos; gênero; mulata; mulher negra.

\section{Resumen}

Este trabajo es parte de la investigación de tesis de maestría en un concurso llamado "Miss Mulata" la ciudad de Arroyo Grande (RS), este corte tiene como objetivo tratar la trayectoria de Deise Nunes. Ella participó en este evento en 1982, y muchas otras competiciones, para ganar el título de Miss Brasil en 1986. Deise se han coronado como el representante del Brasil se opone a varios estereotipos de belleza, contrariamente a un nivel de blancura, en la que los blancos son valorada estupenda. Deise causó sorpresas para representar el estado Gaucho y el país de la mezcla de razas que siempre enviaba a las mujeres blancas de Miss Universo, y preferiblemente rubias. La principal metodología utilizada en esta investigación fue la historia oral, así como la investigación en los archivos de periódicos.

Palabras- claves: Deise Nunes; concursos; gênero; mulata mujer de negro.

\begin{abstract}
This work is part of a master's dissertation research on a competition called "Miss Mulata" the city of Arroyo Grande (RS), this cut is intended to address the trajectory of Deise Nunes. She took part in this event in 1982, and many other competitions, to win the title of Miss Brazil in 1986. Deise have been crowned as the representative of Brazil is opposed to various beauty stereotypes, contrary to a standard of whiteness, in which whites are super valued. Deise caused surprises to represent the Gaucho State and the country of miscegenation that there was always sending to the Miss Universe white women, and preferably blondes. The principal methodology used in this research was the oral history, as well as research in newspaper archives.
\end{abstract}

Words- keys: Deise Nunes; contests; genre; mulatta; black woman.

\footnotetext{
1 Mestra em História; Universidade Federal de Pelotas - UFPel; Pelotas, Rio Grande do Sul, Brasil; biafloor89@gmail.com.
} 


\section{Introdução}

Esta pesquisa é parte de minha dissertação de mestrado em que versava sobre um concurso de beleza intitulado "Miss Mulata" (1969-1999), realizado na cidade de Arroio Grande. O objetivo deste certame era a valorização da beleza da mulher negra, o mesmo em 1988 passa a abranger o Estado do Rio Grande do Sul, então denominado "Miss Mulata Rio Grande do Sul". A questão central da dissertação era sobre a terminologia utilizada para dar nome ao concurso, tendo em vista as construções sobre o ser mulata ligado a estereótipos sexualizados, e em uma espécie de negação da mulher negra.

No Brasil tinha-se a concepção da negatividade da presença negra para a constituição da identidade nacional, para isso, durante os séculos XIX e XX, surge a figura do mestiço.

Ressalta-se que a realidade da mestiça e da mulata, envolve conflitos e domínio colonial. Segundo Munanga (2012), o cruzamento entre, por exemplo, uma mulher branca e um homem negro, era visto no século XIX, como estéril. E que se gerado, seria incapaz de ser "normal", e assim se percebe o preconceito originário contra o mestiço, como fracos física e moralmente.

E é no âmbito de erotização do corpo feminino que se vai persistir, por parte da elite branca, na invenção da mulata, junto ao samba, carnaval e sexo. Originando um conflito maior ainda sobre a mulher negra, pois são seus símbolos de identidade que estão estereotipados e excluídos de conceitos sociais, culturais e de beleza.

Munanga (2008) diz ter os mestiços, desde o período colonial, caído em uma armadilha ao não assumirem a identidade negra, uma política de dividir para dominar, uma desconstrução da solidariedade entre negros e mulatos que repercute até hoje no processo de formação da identidade coletiva de ambos.

Pensar em concursos de beleza e a falta de mulheres negras em muitos deles é pensar nas representações feitas sobre o corpo e estética da mulher negra ou mulata, sobretudo, moral e sexual (GIACOMONI, 2006). Por isso, a importância destes concursos específicos para a auto-estima, sempre ligados à beleza, "as principais estratégias de elevação da autoestima do negro são os cuidados com a beleza e as histórias de sucesso pessoal." (OLIVEIRA, 2010, p.31)

No Brasil a estética é associada a padrões de beleza branca, uma superioridade estética denominada branquitude. O corpo negro como um ícone de feiura, primitivismo, agressividade e descontrole faz parte de um complexo processo histórico, em uma racialização do gênero para administrar o corpo da mulher branca e conter o da mulher negra. 

e-ISSN 2016/Atual: 2525-7870 | e-ISSN 2015/2016: 2447-018X

Fixando as dicotomias pureza/impureza; limpeza/sujeira; contágio/purificação; ordem/desordem. (XAVIER, 2012)

No século XIX padrão de beleza foi associado ao higienismo, que por vez significou clarear. "Havia conselhos que sugeriam a proximidade entre sujeira, doença e pele escura" (SANT' ANNA, 2014, p.75), chamadas de "pele encardida", e estas precisavam ser regeneradas. Com isso, surge cosméticos com promessas de clareamento da pele e alisamento dos cabelos, uma forma violenta de resistir à discriminação. "Em uma sociedade imagética, em que o sujeito é definido por sua aparência, não há como desconsiderar o sofrimento psíquico decorrente de todas as regulações sociais que incidem sobre o corpo- sobretudo o feminino". (NOVAES, 2011, p.477)

A população negra é dividida em negra (preta) e mulata (visualmente menos negra), e estas belezas são racializadas, sendo a mulata, devido à mistura, um sinal de beleza. Mas, uma estética de lugares reservados, em especial para o samba e carnaval. Um estereótipo que concursos negros tentam quebrar. E o Miss Mulata, especificamente, levando em conta o seu período histórico, tenta converter símbolos negros ou mulatos de feiura para o belo.

A classificação de cor no Brasil é definida socialmente, de maneira a levar em conta o fenótipo, ao contrário dos Estados Unidos em que a classificação é racial e hereditária. Para alguns antropólogos como Marvin Harris, o Brasil forma grupos de cor e não de raça (GUIMARÃES, 2012). E esta classificação é diversa, o que se percebeu no Censo Demográfico do IBGE de 1976, que através de uma pergunta aberta sobre cor teve-se 136 tipos de classificação, como, por exemplo, branca, clara, morena clara ou preta. Sendo a categoria "morena (o)" a de preferência (GUIMARÃES, 2012). O que se percebe é a constante dualidade do "preto" e do "branco" nas categorias de cores (GUIMARÃES, 2012). Mas no Brasil esta oposição binária é simplista, segundo Sérgio Costa (2006), pois é uma sociedade plural e complexa. Podemos observar esta afirmação na figura do mestiço.

O sentido, como o da mulata, não é estático e natural, ou seja, é arbitrário e se move pela linguagem, esta por sua vez é um sistema de sinais (HALL, 1997). Tendo o signo uma forma, que pode ser por meio da imagem, fotografia ou palavra; e um conceito ou significado, em que esta forma é associada (HALL, 1997).

Cada um de nós provavelmente entende e interpreta o mundo de um jeito único e individual. No entanto, nós podemos nos comunicar porque compartilhamos praticamente os mesmos mapas conceituais, e, então, tomamos sentidos ou interpretamos o mundo de maneiras grosseiramente iguais. (HALL, 1997, p.5) 
Os signos possuem significados, mas estes não são fixos, e por isso podem receber um novo significado, seja coletivo ou individual. A terminologia mulata foi sendo percebida e transformada. Os grupos de mulheres negras, em sua maioria, não se reconhecem mais como mulatas pelo fato de seu significado pejorativo. Um significado com origem no sistema escravocrata, voltado às questões sexuais. E é exatamente por isso que o concurso também existiu, para reverter o sentido, para positivar a mulher negra e mestiça.

Nesse contexto, podemos localizar a possibilidade da luta ideológica. Uma cadeia ideológica particular se torna um local de luta não apenas quando as pessoas tentam deslocá-la, rompê-la ou contestá-la, suplantando-a por um conjunto inteiramente novo de termos, mas também quando interrompem o campo ideológico e tentam transformar seus significados pela modificação ou rearticulação de suas associações, passando, por exemplo, do negativo para o positivo. (HALL, 2013, p. 213)

Afinal, as terminologias adotadas referem-se às trajetórias e identidades, e fazem parte deste protagonismo negro de tomada de seus sentidos e história. Trajetórias como a de Deise Nunes, um símbolo de beleza negra, e mais do que isso, de sucesso e possibilidades, assim como, a trajetória de cada Miss Mulata de Arroio Grande.

\section{A trajetória de uma Miss Negra}

A grande representação de beleza negra, na cidade de Arroio Grande, percebido nas entrevistas feitas, é a, hoje empresária, Deise Nunes ${ }^{2}$. Esta representação é destacada em um folheto desenvolvido em 1989 para divulgar a nova fase do concurso, em que o Miss Mulata tornou-se Estadual,contando uma breve trajetória de Deise. O título era: "Deise Nunes- daqui para o Brasil e o Mundo", valorizando a descoberta, primeiramente, em Arroio Grande, destacando sua passagem pelo Miss Mulata até o Miss Universo, um símbolo de beleza para a sociedade negra arroio-grandense.

Deise foi Miss Mulata Arroio Grande em 1982, e segundo lugar no Miss Mulata Rio Grande do Sul; mas seu destaque se deu em 1986 quando foi eleita Miss Brasil e foi finalista do Miss Universo, a primeira mulher negra a representar este país.

Nascida em Porto Alegre, em 3 de março de 1968, incentivada por sua mãe, que tinha muitos amigos na cidade de Arroio Grande, Deise acaba debutando no Clube Guarani e representando a cidade no Miss Mulata Zona Sul em 1982, neste período o concurso abarcava apenas a região sul do Estado.

\footnotetext{
${ }^{2}$ Atualmente, utiliza o nome de casada, Deise Nunes Ferst.
} 
RELACult - Revista Latino-Americana de Estudos em Cultura e Sociedade

Revista Latinoamericana de Estudios en Cultura y Sociedad | Latin American Journal of Studies in Culture and Society

V. 02, Ed. Especial, dezembro, 2016, p. 349-361| periodicos.claec.org e-ISSN 2016/Atual: 2525-7870 | e-ISSN 2015/2016: 2447-018X

Ela não vence o concurso Miss Mulata que foi realizado em Santa Vitória do Palmar, mas conquista o segundo lugar, o de primeira princesa. Deise diz achar importante estes concursos mais específicos, pois, segundo ela, "tu te encontras, tu te vê!", mas também acredita que as meninas negras devem participar de outros concursos, vencer seus medos.

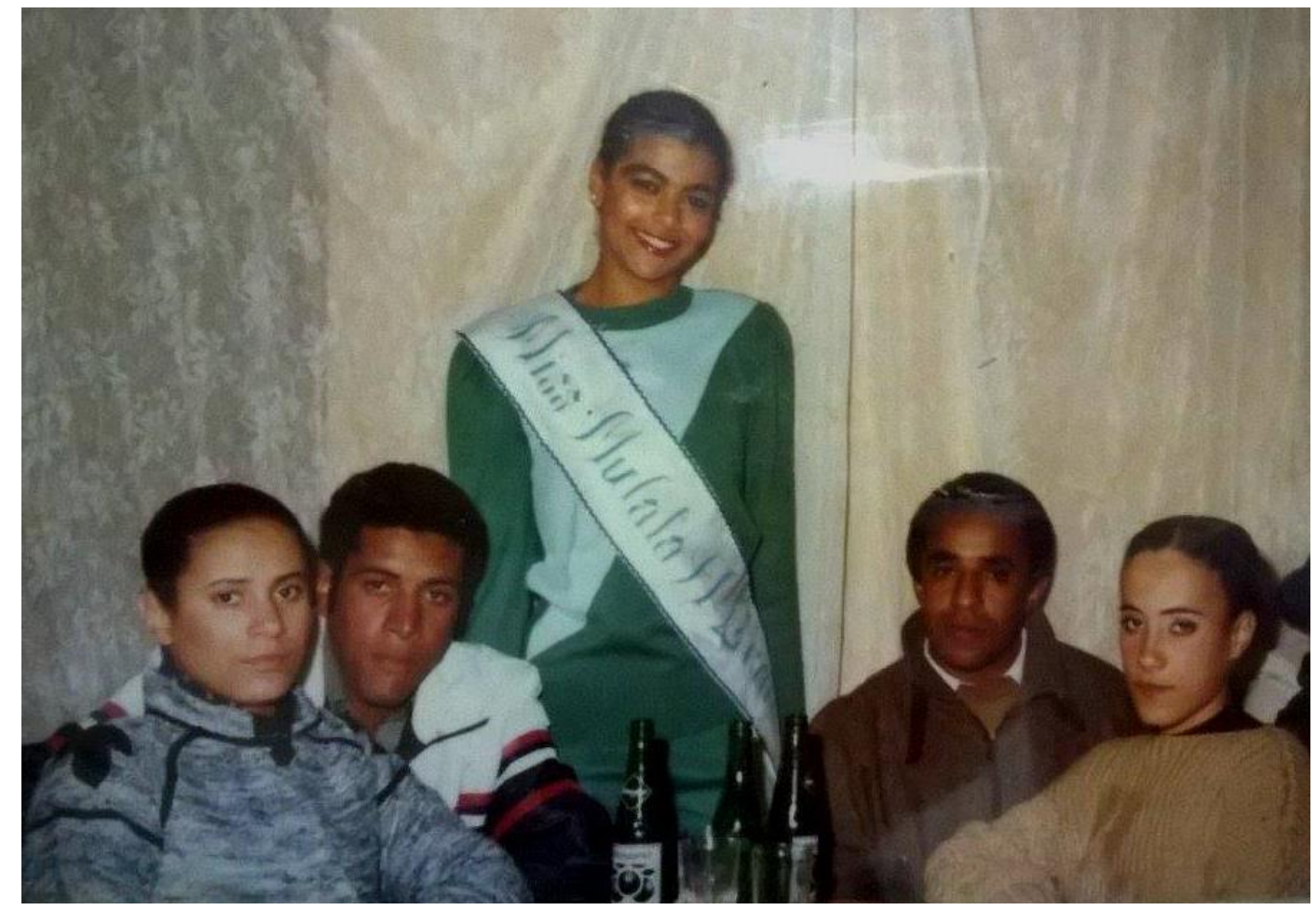

Fotografia 1- Deise Nunes: Miss Mulata Arroio Grande 1982

Fonte: Acervo Pessoal de Antônio Carlos da Conceição

Deise Nunes se autodefine como negra. Diz ser filha de mãe negra e pai branco, e que quando nasceu foi colocada em sua certidão a classificação de parda, por ser bem clara. Mas se questiona: "é muito engraçado, assim, porque na minha certidão eu sou parda, eu não sou nem branca, nem negra, eu sou parda. Que raça é essa? Parda? Não existe essa raça! Não existe a cor, parda é cor do nada!”. E sobre a terminologia do concurso em Arroio Grande, fala sobre conceitos da época:

Naquele época, não se falava negro, as pessoas não diziam negro, porque parecia que tu dizia negro tu tava ofendendo. Então as pessoas diziam moreno claro, moreno escuro, mulata, mulato, sabe? Mas não dizia negro!(Deise Nunes)

Ressalta que o negro tem diversas tonalidades, sem deixar de ser negro, e que hoje o concurso poderia aderir à palavra negra, e não mulata. Segundo ela, a raça negra é 
estigmatizada desde os tempos de escravidão no Brasil, afirma que a discriminação e racimo são históricos.

Deise foi criada por uma família branca, assim como sua mãe, os quais chama de avós. Ela conta a história de que eles temiam que ela sofresse a violência do racismo, em especial, quando pretendia conhecer a família de um namorado branco que teve na adolescência. Ela disse que na época não entendia do porquê que poderia ser um problema, mas sob orientação de sua família acabou não indo ao encontro.

Atualmente, seu marido também é branco, com o qual tem um casal de filhos. Deise acaba se encaixando nas baixas estatísticas de mulheres negras casadas, quando comparadas com brancas, em especial, casadas com homens brancos. Isto se dá pela afetividade da mulher negra que é explorada, violentada e desvalorizada esteticamente desde períodos coloniais. No Brasil, os estereótipos estão também ligados à servidão profissional e sexual (PACHECO, 2013).

Entre o Miss Mulata e o Miss Brasil, Deise, participou de muitos concursos até se tornar mundialmente conhecida. Em 1977 foi Miss Simpatia do colégio; em 1982 foi primeira princesa no Miss Brotinho, um concurso do clube de futebol Grêmio de Porto Alegre; em 1983, foi primeira princesa no Rainha do Colégio, que com a desistência do primeiro lugar, ela acabou levando o titulo, representando o seu colégio no Miss UNESPA, e ganhando mais este concurso, em que foi comparada à Marina Montili, famosa modelo negra e carioca. Segundo ela, neste período começou a perceber questionamentos sobre a sua cor.

Mas o concurso que marcou, não apenas de forma positiva, foi o Rainha das Piscinas quando tinha 16 anos, em 1984. O concurso estadual era bem tradicional na cidade de Porto Alegre, teve origem em 1953. Deise representou seu time de futebol, o Sport Club Internacional, foi a única mulher negra a participar em todos os anos do concurso. E seu ano foi o último. O concurso foi realizado no Gigantinho ${ }^{3}$, havia 68 candidatas. Segundo ela, o resultado demorou muito a sair naquele dia, foi então, que depois descobriu o motivo. Um dos jurados não aceitava a vitória de Deise Nunes no concurso, e a contagem de votos foi feita três vezes. Ao final, os outros jurados deram um ultimato: ou Deise era coroada, ou não haveria vencedora. Deise foi coroada a Rainha das Piscinas de 1984. Ela disse que muitas mães de outras candidatas ficaram chateadas e inconformadas com o resultado. Deise ficou muito abalada, querendo desistir de participar de concursos de beleza.

\footnotetext{
${ }^{3}$ Ginásio Poliesportivo, ligado ao Beira Rio, parte do Sport Club Internacional de futebol (POA).
} 

e-ISSN 2016/Atual: 2525-7870 | e-ISSN 2015/2016: 2447-018X

Mas depois disso, eu lembro que foi uma coisa que me incomodou bastante! Aí, sabe, quer saber de uma coisa? Eu não vou participar de concurso nenhum (?) porque que eu vou participar? Pra ficar sendo discriminada por essa gente. ah não vou mais, não quero mais concorrer! "olha mãe, eu não quero mais saber desse negócio de concurso, não quero mais saber, chega, deu, basta! ". Mas ela não ficou satisfeita com isso, e ela foi no SBT então, depois que fiz 18 anos, ela me inscreveu pro Miss Rio Grande do Sul. (Deise Nunes)

\section{Miss Brasil 1986}

Por muitos anos, o Miss Brasil foi feito através do SBT, segundo Deise, cada programa do canal cobria uma eliminatória. Deise, após ganhar o Miss Rio Grande do Sul, foi para a eliminatória em São Paulo. Apesar de declarar que não sofreu nenhum preconceito por parte da organização do concurso, ou de candidatas, não nega que foi um espanto para os expectadores.

Então, foi assim, o maior espanto, claro, compreensível até então, "Como assim, no Rio Grande do Sul tem negro?", não é? Porto Alegre, eu nasci no Rio Grande do Sul, me criei lá, moro lá até hoje! (?), "Não, porque o Rio Grande do Sul nunca mandou uma negra, sempre foi loira!"

Eu era a única! Então, eu era a única diferente ali. (Deise Nunes)

Antes de Deise, tivemos a beleza negra de Vera Lúcia Couto dos Santos com o segundo lugar no Miss Brasil 1964. Mas Deise ainda foi a primeira mulher negra a representar o Brasil no Miss Universo.

Muitos questionaram sobre a origem de Deise Nunes, sobre ela ser baiana ou pernambucana, mas criada no sul. Deise tinha sempre de afirmar ser gaúcha nascida em Porto Alegre.

Durante as eliminatórias do concurso, através de fotos e vídeos, percebe-se que Deise nunca negou sua negritude. Ela disse nunca ter alisado para concursos, mas usava um gel para tirar um pouco do volume dos fios, mas que, inclusive, no Miss Brasil foi sugestão do cabeleireiro de deixar seu cabelo armado e bem natural. O que também podemos perceber que era moda o cabelo mais armado nos anos 80 .

Porque muitas fazem coque né, muitas fazem coque, isso, aquilo! Não, liberei! Soltei, simplesmente! E usava meu cabelo solto todos os dias, toda hora! (Deise Nunes) 

e-ISSN 2016/Atual: 2525-7870 | e-ISSN 2015/2016: 2447-018X

O concurso tinha desfile de maiô, gala, e traje típico, além de entrevistas e sessões de fotos. O traje típico de Deise no Miss Brasil foi um traje gaúcho, mas estilizado. Deise confessa que demorou a entender a grandiosidade do título de Miss Brasil 1986.

Eu fui me dar conta da importância do título, assim, para minha raça, para os negros, para a auto-estima de muitas, acho que três dias depois que caiu a ficha assim. Não é a ficha 'eu sou a mulher mais linda do Brasil! ' Não! A ficha que caiu 'Poxa, eu serei a representante da beleza da mulher brasileira no Miss Universo! (Deise Nunes)

Após ter vencido o Miss Brasil, Deise passa a representar seu país no concurso Miss Sudamérica, em Caracas, onde a vencedora foi a representante da Venezuela, como Primeira Princesa ficou a representante da Colômbia. Deise ganhou o título de Segunda Princesa e melhor traje típico. No Miss Universo, realizado no Panamá, Deise ficou em sexto lugar, ela acabou não se saindo muito bem na entrevista, segundo sites. Segundo ela, deveu-se a sua pouca idade, inexperiência.

\begin{abstract}
"Mas eu com certeza ali que deve ter me atrapalhado foi a minha idade, falta de experiência, acho que se eu tivesse ido com um pouco mais de idade, com 20anos, com 21 anos, mais madura, se eu tivesse vivido mais, ter sido mais experiente, talvez eu tivesse, não vou dizer que talvez eu tivesse ganho o concurso, mas talvez eu tivesse ficado melhor colocada, ou talvez tivesse até vencido o concurso! (Deise Nunes)
\end{abstract}

A figura de Deise, enquanto mulher negra, foi representada através de estigmas sobre seu corpo. Como exemplo na revista "Manchete", na qual a capa parece reconhecer a relevância do título de Miss Brasil para a raça negra no país, mas não se pode dizer o mesmo na sequência da matéria, em que a frase "Beleza Negra tipo exportação" remete a uma beleza incomum que acaba agradando o estrangeiro, uma beleza exótica, além, obviamente, de transformar a beleza negra como um produto. O que leva a fazer uma relação com os cursos, em especial, no Rio de Janeiro nos anos de 1980 a 1990 para formar mulatas profissionais, as quais geralmente acabavam trabalhando no exterior, a maioria como dançarinas. Para ser uma mulata era necessário ter características negras, como a cor, e saber sambar. Representa a sensualidade brasileira, este imaginário não produz apenas uma representação estética da mulata brasileira, mas também uma representação moral e sexual da mulata (GIACOMINI, 2006). 
RELACult - Revista Latino-Americana de Estudos em Cultura e Sociedade

Revista Latinoamericana de Estudios en Cultura y Sociedad | Latin American Journal of Studies in Culture and Society V. 02, Ed. Especial, dezembro, 2016, p. 349-361| periodicos.claec.org e-ISSN 2016/Atual: 2525-7870 | e-ISSN 2015/2016: 2447-018X

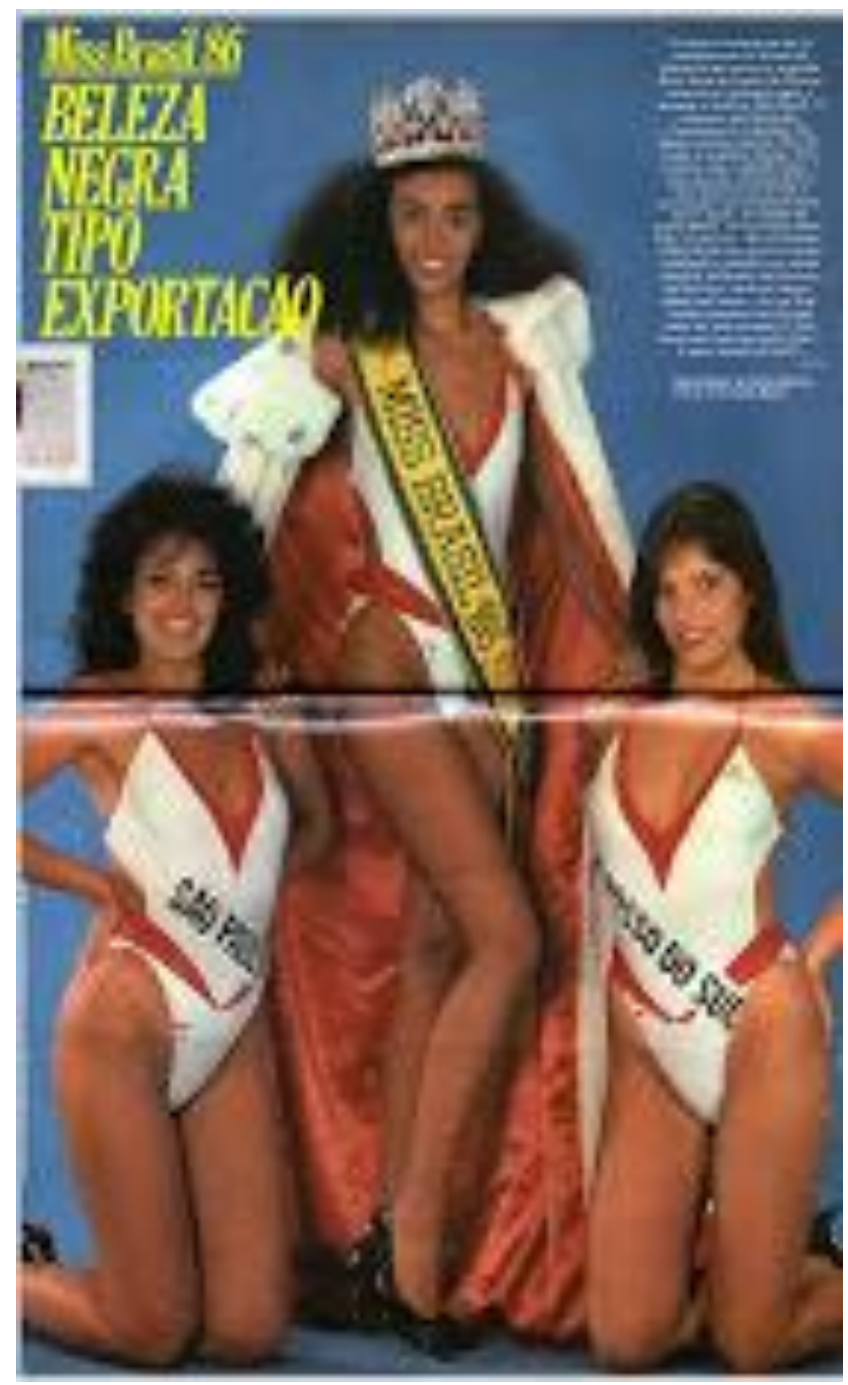

Fotografia 2 - Beleza Negra tipo exportação Fonte: Revista Manchete 1986- Matéria 


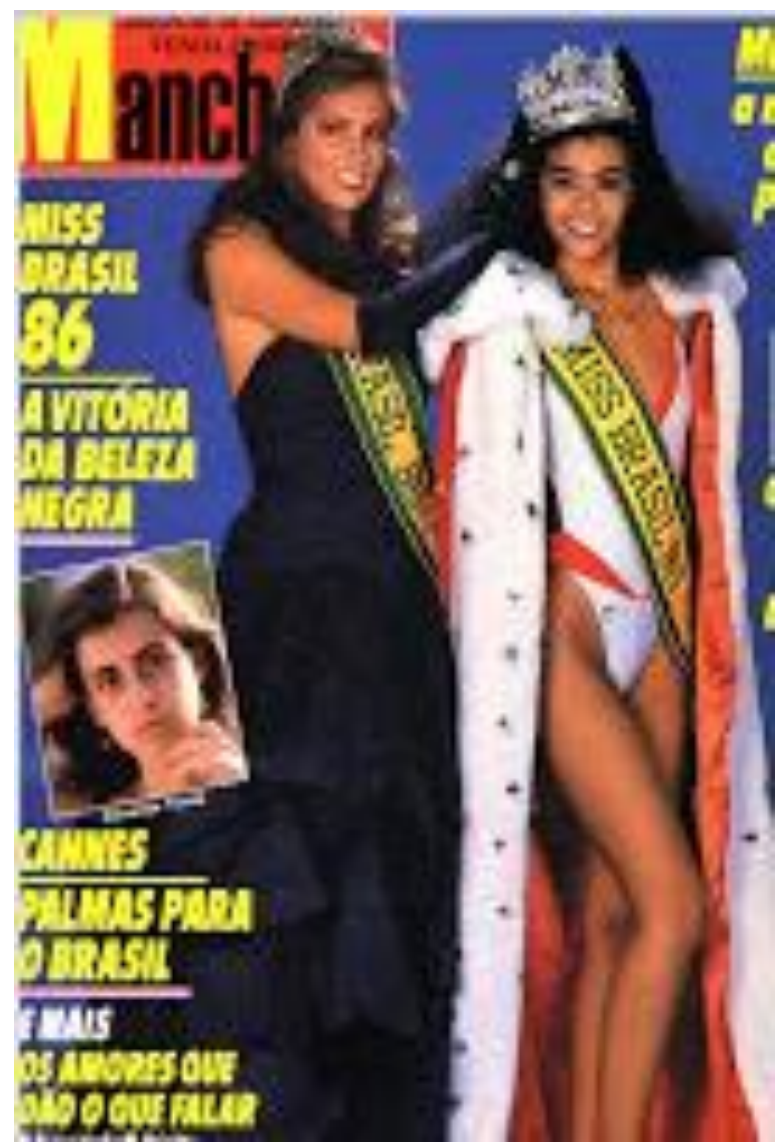

Fotografia 3- Beleza Negra tipo exportação Fonte: Revista Manchete 1986- Matéria

Sobre a presença de Deise no Miss Universo, ela diz ter ficado mais a vontade, pois não era a única mulher negra como candidata à mais bela. Mas foi uma surpresa para os outros países o Brasil ser representado por uma mulher negra.

Então, as pessoas olhavam assim "nossa, o Brasil mandou uma negra, ué, como assim!", até então o Brasil não tinha mandado, somente agora. Mas foi assim, bom lá eu encontrei vários (?) tinha negras de todos os lados, as africanas, tem várias ali, vários países. Tinha a Miss França que eu podia considerar ela uma negra, por causa da pele bem escura, era bem mais escuro do que o moreno, digamos. Então são várias negras! (Deise Nunes)

Segundo Deise, para todos foi uma novidade o Brasil não ser representado por uma mulher branca e loira. Ela também chama a atenção para a variedade de cores da pele negra, ao contrário do imaginário brasileiro. 
Muitas roupas e trajes foram emprestados à Deise para poder participar do concurso, diz que sua mãe teve de assinar um termo de responsabilidade sobre algumas roupas e acessórios emprestados. São muitos gastos para um concurso de beleza. Ressalta também, que aprendeu muito nestes períodos, conheceu culturas, um pouco do mundo, enfim, que valeu a pena.

Atualmente, Deise Nunes participa de muitos concursos como jurada, inclusive no Miss Rio Grande do Sul, e diz estar a espera de mais uma Miss Negra representado o Estado, ou até mesmo, o Brasil.

\footnotetext{
"Deise, pô faz tanto tempo, 30 anos que sabe", aí eu digo "ah gente, peraí eu to procurando!" Nós vamos achar, um dia vamos achar. (?) elas tem que vir participar! Como assim? Não vai surgir do nada! Tem que se mostrar tem que participar, ela tem que ir para o concurso! (Deise Nunes)
}

A Miss coloca que as meninas negras devem se mostrar mais nestes concursos, preencher estes lugares, como forma de empoderamento, "“

A referência é importante, e muito importante! Eu mesmo tive minhas referências, tinha modelos que eu admirava muito, uma daqui e outra do Rio de Janeiro, então foi uma referência, eu olhava elas assim (?), "ah meu Deus, um dia eu quero ser assim! ". Então eu tinha as minhas referências, todo mundo tem! E é bacana tu poder ser referência (?), e o meu trabalho é de estimular, e é o que eu mais quero! Que ganhe todas! (?) eu acho que só tem que ser sem medo, o medo tem que tá dormindo (?) e depois sentir pena por ter desistido! (Deise Nunes)

Deise é uma referência para muitas meninas negras, em especial, na cidade de Arroio Grande. Ela diz saber desta importância, de estimular a participação de mulheres negras em espaços de beleza. Mas, ainda nos dias de hoje, a beleza que predomina é a branca como referência universal. Por isso, Deise coloca que as mulheres negras devem ocupar estes lugares, indo contra a branquitude normativa.

Neste ano de 2016, o desejo de Deise de ter uma mulher negra como representante brasileira no Miss Brasil se realizou, representando o Paraná, a Miss Brasil 2016 é Raissa Santana. Uma representação negra do sul do país, região em que o silenciamento da presença negra ainda está em desconstrução.

Enfim, Deise e Raissa representam a luta de milhares de mulheres negras por pertencimento e reconhecimento que vai além da beleza. É através de uma trajetória como a de Deise que se reconhece e entendesse a história da sociedade brasileira enquanto racista, apesar de sua dita identidade negra e mestiça. 


\section{Referências Bibliográficas}

FIGUEIREDO, Ângela. "Cabelo, cabeleira, cabeluda e descabelada”: Identidade, Consumo e manipulação da aparência entre os negros brasileiros. XXVI Reuniaão Anual da Associação Nacional de Pós- Graduação e pesquisa em Ciências Sociais, Caxambu, Outubro de 2002.

GIACOMINI, Sonia Maria. A Alma da Festa: família, etnicidade e projetos num clube social da Zona Norte do Rio de Janeiro. O Renascença Clube. Belo Horizonte: Editora UFMG; Rio de Janeiro, IUPERJ, 2006.

GUIMARÃES, Antônio Sérgio Alfredo. Preconceito Racial: modos, temas e tempos. 2 ed. São Paulo: Cortez, 2012.

GOMES, Nilma Nilo. Sem Perder a Raíz: Corpo e cabelo como símbolos da identidade negra. Belo Horizonte: Autêntica, 2008.

HALL, Stuart. Da diáspora: identidades e mediações culturais. 2ed. Belo Horizonte: Editora UFMG, 2013.

HALL, Stuart. The work of representation. In: HALL, Stuart (Org.) Representation: Cultural representation and cultural signifying practices. London/Thousand Oaks/New Delhi:

Sage/Open University, 1997. Pág. 15-64

MUNANGA, Kabengele. Negritude: Usos e Sentidos. 3. ed, Belo Horizonte: Auntêntica Editora, 2012.

MUNANGA, Kabengele. Rediscutindo a mestiçagem no Brasil: identidade nacional versus identidade negra. 3ed. Belo Horizonte: Autêntica, 2008.

NOVAIS, Joana de Vilhena. Beleza e feiura: corpo feminino e regulação social. IN:

DELPIORE, Mary Del; AMANTINO, Márcia (org.). História do corpo no Brasil. São Paulo: Editora Unesp, 2011.

OLIVEIRA, Carolina dos Santos de. Adolescentes Negras: relações raciais, discurso e mídia impressa feminina na contemporaneidade. Belo Horizonte: Nandyala, 2010.

PACHECO, Ana Cláudia Lemos. Mulher Negra: afetividade e solidão. Salvador: ÉDUFBA, 2013.

SANT' ANNA, Mara Rúbia. Concurso de Beleza: discursos e sujeitos. III Colóquio Nacional de Moda; 2014; Universidade Federal de Santa Catarina. Florianopolis: UDESC,2014.

SCHUCMAN, Lia Vainer. Entre o "encardido", o "branco" e o "branquíssimo": raça, hierarquia e poder na construção da branquitude paulistana. Tese de Doutorado- Programa de Pós- Graduação em Psicologia. Instituto de psicologia de São Paulo. São Paulo, 2012.

SOVIK, Liv. Aqui ninguém é branco. Rio de Janeiro: Aeroplano, 2009. 
RELACult - Revista Latino-Americana de Estudos em Cultura e Sociedade

Revista Latinoamericana de Estudios en Cultura y Sociedad | Latin American Journal of Studies in Culture and Society V. 02, Ed. Especial, dezembro, 2016, p. 349-361 | periodicos.claec.org e-ISSN 2016/Atual: 2525-7870 | e-ISSN 2015/2016: 2447-018X

XAVIER, Giovana. Brancas de almas negras?: beleza, racialização e cosmética na imprensa negra pós- emancipação (Estados Unidos, 1890-1930), Campinas. São Paulo: 2012.

Acesso em: 27 de agosto de 2016. 